\title{
Therapy with mesenchymal stromal cells or conditioned medium reverse cardiac alterations in a high-fat diet-induced obesity model
}

\author{
P.S. DALTRO ${ }^{1,2}$, B.C. BARRETO ${ }^{1,3}$, P.G. SILVA ${ }^{4}$, P. CHENAUD NETO ${ }^{4}$, \\ P.H.F. SOUSA FILHO ${ }^{4}$, D. SANTANA NETA ${ }^{4}$, G.B. CARVALHO ${ }^{1}$, D.N. SILVA ${ }^{1}$, \\ B.D. PAREDES ${ }^{1}$, A.C. DE ALCANTARA ${ }^{1}$, L.A.R. FREITAS ${ }^{4,5}$, R.D. COUTO $^{6}$, R.R. SANTOS ${ }^{1,7}$, \\ B.S.F. SOUZA ${ }^{1,5,7}$, M.B.P. SOARES ${ }^{1,5,7}$ \& S.G. MACAMBIRA ${ }^{1,5,7,8}$ \\ ${ }^{1}$ Center for Biotechnology and Cell Therapy, Salvador, BA, Brazil, ${ }^{2}$ Multicentric Program in Biochemistry and \\ Molecular Biology, Federal University of Bahia, Salvador, BA, Brazil, ${ }^{3}$ Faculty of Biology, Federal University of \\ Bahia, Salvador, BA, Brazil, ${ }^{4}$ Faculty of Medicine, Federal University of Bahia, Salvador, BA, Brazil, ${ }^{5}$ Gonçalo \\ Moniz Institute, Oswaldo Cruz Foundation (FIOCRUZ), Salvador, BA, Brazil, ${ }^{6}$ Faculty of Pharmacy, Federal \\ University of Bahia, Salvador, BA, Brazil, ${ }^{7}$ National Institute of Science and Technology for Regenerative Medicine, \\ Rio de Faneiro, RF, Brazil, and ${ }^{8}$ Department of Biochemistry and Biophysics, Institute of Health Sciences, Federal \\ University of Bahia, Salvador, BA, Brazil
}

\begin{abstract}
Background. Obesity is associated with numerous cardiac complications, including arrhythmias, cardiac fibrosis, remodeling and heart failure. Here we evaluated the therapeutic potential of mesenchymal stromal cells (MSCs) and their conditioned medium (CM) to treat cardiac complications in a mouse model of high-fat diet (HFD)-induced obesity. Methods. After obesity induction and HFD withdrawal, obese mice were treated with MSCs, CM or vehicle. Cardiac function was assessed using electrocardiography, echocardiography and treadmill test. Body weight and biochemical parameters were evaluated. Cardiac tissue was used for real time (RT)-polymerase chain reaction (PCR) and histopathologic analysis. Results/ Discussion. Characterization of CM by protein array showed the presence of different cytokines and growth factors, including chemokines, osteopontin, cystatin C, Serpin E1 and Gas 6. HFD-fed mice presented cardiac arrhythmias, altered cardiac gene expression and fibrosis reflected in physical exercise incapacity associated with obesity and diabetes. Administration of MSCs or CM improved arrhythmias and exercise capacity. This functional improvement correlated with normalization of GATA4 gene expression in the hearts of MSC- or CM-treated mice. The gene expression of connexin 43, troponin I, adiponectin, transforming growth factor (TGF) $\beta$, peroxisome proliferator activated receptor gamma (PPAR $\gamma$ ), insulin-like growth factor 1 (IGF-1), matrix metalloproteinase-9 (MMP9) and tissue inhibitor of metalloproteinases 1 (TIMP1) were significantly reduced in MSCs, but not in CM-treated mice. Moreover, MSC or CM administration reduced the intensity of cardiac fibrosis. Conclusion. Our results suggest that MSCs and CM have a recovery effect on cardiac disturbances due to obesity and corroborate to the paracrine action of MSCs in heart disease models.
\end{abstract}

Key Words: cardiac dysfunction, cell therapy, mesenchymal stromal cells, obesity

\section{Introduction}

Obesity and excessive consumption of dietary fats have deleterious consequences to the metabolism and heart function, being strongly linked to the progression of type 2 diabetes mellitus (DM2) and heart disease $[1,2]$. Obesity has been associated with structural and functional changes in the heart, including arrhythmias, cardiac fibrosis and subclinical impairment of left ventricle systolic and diastolic functions. Some cardiac alterations associated with structural and electrical remodeling are irreversible and can lead to heart failure, increasing the risk for sudden death through mechanisms that are not completely elucidated [3].

In addition to the electrical remodeling and severe arrhythmias, long-standing obesity is also associated with structural remodeling, characterized by eccentric hypertrophy and followed by diastolic dysfunction and fibrosis, despite coronary disease or hypertension [4-6]. When isolated from other cardiac

Correspondence: Simone Garcia Macambira, PhD, Department of Biochemistry and Biophysics, Institute of Health Sciences, Federal University of Bahia, Av. Reitor Miguel Calmon s/n-Vale do Canela, Salvador, BA 40.110-100, Brazil. E-mail: simonegm@ufba.br 
impairments, this disease state is referred to as diabetic cardiomyopathy [7].

Cell-based therapies are currently under investigation and hold promise to treat cardiac diseases. Mesenchymal stromal cells (MSCs) are among the most-studied cell types in the cardiovascular field. MSCs are multipotent cells easily isolated from different tissues in the adult, being expandable in vitro as plastic-adherent cells with fibroblast-like morphology, with potential for differentiation into tissues of mesodermal origin and displaying immunomodulatory properties $[8,9]$. Pre-clinical and clinical studies have shown beneficial effects of MSCs in injured hearts, leading to reduction of fibrosis [10], stimulation of angiogenesis [11] and restoration of contractile function [12]. In cardiac diseases, the beneficial effects of MSCs are primarily explained as the result of release of paracrine factors [11,13-15], which regulate several biological processes. This hypothesis is further supported by the observation that MSC conditioned medium (CM) also enhances cardiac tissue repair $[16,17]$, being used for treatment of cardiac ischemia lesions, as previously shown $[17,18]$.

Despite the growing body of evidence, there are no reports showing the effects of cell therapy and cardiac remodeling in the presence of arrhythmias and physical disability due to obesity. In the present study, we investigated the therapeutic effects of bone marrow-derived MSCs and its CM in an experimental model of cardiac alterations by obesity induction in $\mathrm{C} 57 \mathrm{Bl} / 6$ mice fed with a diet enriched with lard saturated fat.

\section{Materials and methods}

\section{Animals and obesity induction}

Six-week-old male C57B1/6 mice were housed at the animal facility of the Center for Biotechnology and Cell Therapy, São Rafael Hospital (Salvador, Brazil), in a room with constant temperature $\left(20 \pm 2^{\circ} \mathrm{C}\right)$, controlled humidity (50\%), free access to food and water ad libitum and exposure to a constant light-dark cycle of $12 \mathrm{~h}$ and $12 \mathrm{~h}$. All animal protocols were approved by the Ethical Committee for Animal Research of Gonçalo Moniz Institute, Oswaldo Cruz Foundation.

All mice were fed a standard mouse chow for up to 6 weeks of age. Mice were then divided into two groups: standard diet (Nuvital; $\mathrm{n}=10$ ) and high-fat diet (HFD; Pragsoluções Biociências; $n=28$ ) for 36 weeks, for obesity induction. The composition of the diets is shown in Table I. The time of exposure to HFD was based on our previous study [19] in which we standardized the model of obesity and DM2 in C57BL/6 mice.

\section{Treatment with MSCs and CM}

After 36 weeks of obesity induction, HFD was withdrawn and replaced by regular chow. Obese mice were randomly divided into three subgroups depending on treatment administered: (i) MSCs $(n=10)$, in which intravenous (i.v.) administrations of MSCs $\left(5 \times 10^{5}\right.$ cells/mouse), suspended in $100 \mu \mathrm{L}$, were performed through the tail vein, on 2 consecutive days; (ii) MSC CM $(n=10)$ or (iii) Dulbecco's Modified Eagle's

Table I. Composition of standard diet and HFD.

\begin{tabular}{|c|c|c|c|c|c|}
\hline \multicolumn{3}{|c|}{ HFD $60 \%$ integral } & \multicolumn{3}{|l|}{ Control diet } \\
\hline & $\mathrm{g} \%$ & $\mathrm{kcal} \%$ & & $\mathrm{~g} \%$ & $\mathrm{kcal} \%$ \\
\hline Protein & 23.4 & 17.5 & Protein & 16.8 & 16.4 \\
\hline Carbohydrate & 33.2 & 24.69 & Carbohydrate & 74.3 & 73.1 \\
\hline Fat & 34.6 & 57.9 & Fat & 4.8 & 10.5 \\
\hline Total & & & Total & & \\
\hline $\mathrm{Kcal} / \mathrm{g}$ & 3.87 & 100 & $\mathrm{Kcal} / \mathrm{g}$ & 4.07 & 100 \\
\hline Ingredients & $\mathrm{g}$ & kcal & Ingredients & $\mathrm{g}$ & kcal \\
\hline Dry matter & 95.7 & 0 & Casein, 30 mesh & 228 & 912 \\
\hline Gross fiber & 4.2 & 0 & DL-methionine & 2 & 0 \\
\hline Corn starch & - & 928 & Maltodextrin 10 & 170 & 680 \\
\hline Sucrose & 10.0 & 400 & Corn starch & 835 & 3340 \\
\hline Soybean oil & 8.6 & 774 & Sucrose & 0 & 0 \\
\hline Lard & 24.7 & 2223 & Soybean oil & 25 & 225 \\
\hline Mineral mix & 4.6 & 0 & Coconut oil, hydrogenated & 40 & 360 \\
\hline Sodium & 2.1 & 0 & Mineral mix S10001 & 40 & 0 \\
\hline Potassium & 4.60 & 0 & Sodium bicarbonate & 10.5 & 0 \\
\hline \multirow[t]{4}{*}{ Calcium } & 4.76 & 0 & Potassium citrate, $1 \mathrm{H}_{2} \mathrm{O}$ & 4 & 0 \\
\hline & & & Vitamin mix V10001 & 10 & 40 \\
\hline & & & Choline bitartrate & 2 & 0 \\
\hline & & & FD\&C yellow dye \#5 & 0.1 & 0 \\
\hline Total & 159.26 & 4325 & & 1366.6 & 5557 \\
\hline
\end{tabular}




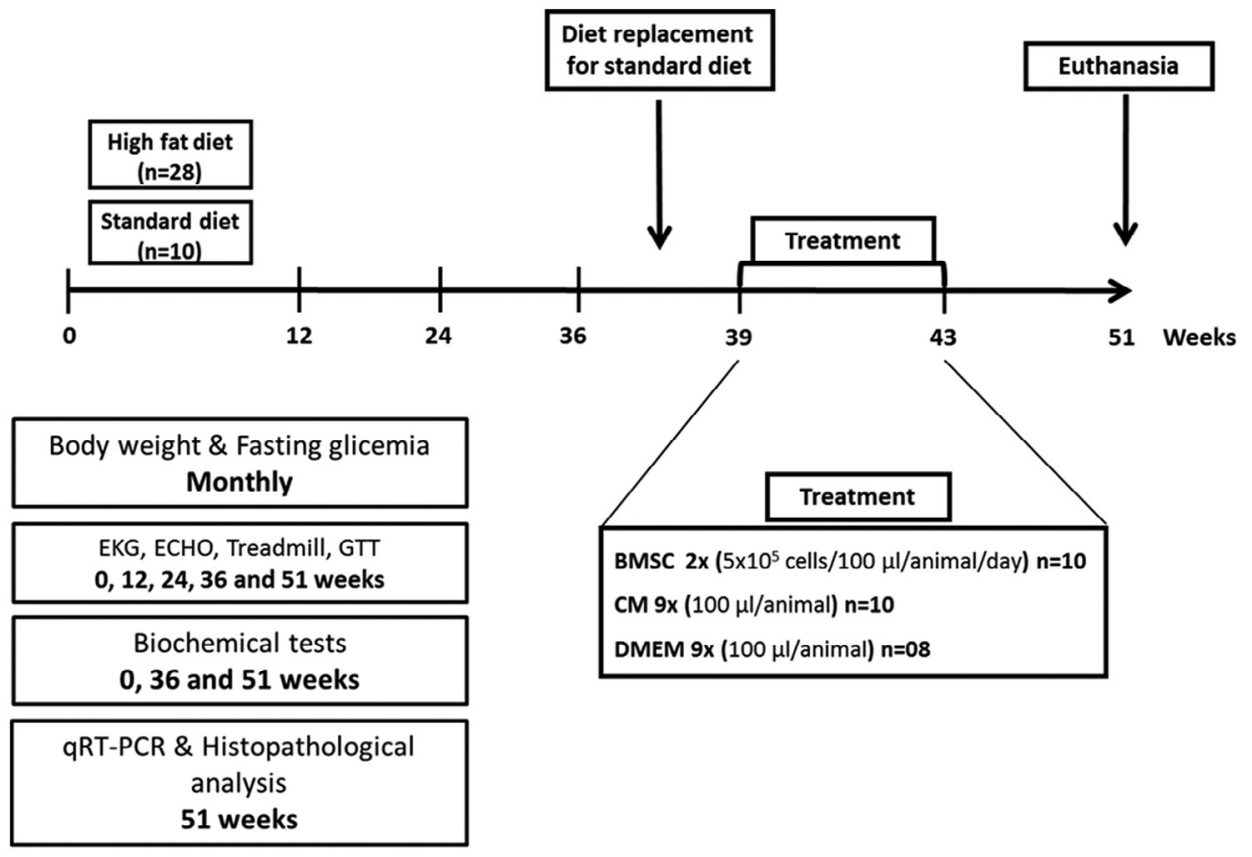

Figure 1. Experimental design. C57Bl/6 mice were fed with HFD or standard diet during the first 36 weeks. Subsequently, the HFD-fed mice had diet replacement for standard and were divided into three groups that received MSC treatment: two injections i.v. (by the tail vein), with a 24-h interval; CM or DMEM treatment, $100 \mu \mathrm{L}$ i.v./animal, in three courses of three injections every other day; and 9-day interval between one cycle to the other. Animals were monitored during all experiment models in specific periods, including at 8 weeks after the end of treatment (51 weeks).

Medium (DMEM; $\mathrm{n}=8$; Gibco), consisting of $100 \mu \mathrm{L} /$ mouse of CM or DMEM, respectively, administered by i.v. route, following a protocol of three courses of three injections with a 1-day interval between each injection, and 9 days between each course. Mice were euthanized 2 months after the end of the therapy, under anesthesia with 5\% ketamine (Vetanarcol; Konig) and $2 \%$ xylazine (Sedomin; Konig). The experimental design is shown in Figure 1.

\section{Culture of MSCs and preparation of CM}

MSCs were obtained from the marrow of femurs and tibiae of $\mathrm{C} 57 \mathrm{Bl} / 6$ mice, after culture and expansion in DMEM supplemented with $10 \%$ fetal bovine serum (FBS) (ThermoFisher Scientific), $100 \mathrm{IU} / \mathrm{mL}$ penicillin (Pen) and $100 \mathrm{mg} / \mathrm{mL}$ streptomycin (Strep; ThermoFisher Scientific). Culture medium was replaced every 3 days, and, upon reaching $90 \%$ confluence, adherent cells were passaged with trypsinethylenediaminetetraacetic acid (EDTA) $0.05 \%$ (ThermoFisher Scientific) and transferred to tissue culture flasks containing medium supplemented with $10 \%$ FBS and $1 \%$ Pen/Strep. CM was prepared using MSCs in passage 4 , with $80-90 \%$ confluence. Cells were washed twice with phosphate-buffered saline (PBS) and transferred to a serum-free DMEM without phenol red, supplemented with Pen/Strep, during $48 \mathrm{~h}$. The CM was then collected and concentrated $25 \times$ by centrifugation at $3000 \mathrm{~g}$ for $50 \mathrm{~min}$ at $20^{\circ} \mathrm{C}$ using a Centriprep $3 \mathrm{kd}$ filtration system (Millipore) and was stored at $-80^{\circ} \mathrm{C}$ until use. Equivalent medium kept under the same conditions in flasks without cells was prepared and used as control.

\section{Phenotypic and multipotency characterization of MSCs}

MSCs were trypsinized, resuspended in $0.9 \%$ saline solution and used for immunophenotyping. MSCs $\left(5 \times 10^{5}\right.$ cells $)$ were incubated for $5 \mathrm{~min}$ with antiCD16/CD32 (BD Biosciences), followed by incubation at $4{ }^{\circ} \mathrm{C}$ for $30 \mathrm{~min}$ with the following antibodies (diluted at 1:100): Phycoerythrin-Cyanine5.5 (Sca1-PECy5.5) (Caltag Medsystems); allophycocyanin (CD90.2-APC), Phycoerythrin (CD117-PE, CD45APC), CD34-Alexa Fluor 647 and CD44-PE (BD Biosciences) and CD29-APC and CD105-PE (BioLegend). Isotype-identical antibodies were used as controls. After incubation and two washes with PBS, data were acquired and analyzed on an LSR Fortessa flow cytometer (BD Biosciences). At least 50000 events were collected and analyzed.

To evaluate the differentiation potential of MSCs, we performed the trilineage differentiation assay (adipogenic, osteogenic and chondrogenic) using specific kits, following manufacturer's instructions (ThermoFisher Scientific). Cultures were stained with oil red $\mathrm{O}$, alcian blue and alizarin red $\mathrm{S}$ stainings 
(Sigma-Aldrich) to assess adipogenic, chondrogenic and osteogenic differentiation, respectively.

\section{Characterization of CM}

The analysis of protein contents of CM was done using the Proteome Profile Array Mouse XL Cytokine Array Kit (R\&D Systems), according to the manufacturer's instructions. Detection was done by chemiluminescence reaction and quantified by densitometry using ImageJ software (National Institutes of Health) and Gilles Carpentier's Protein Array Analyzer macro [20].

Assessment of body weight, fasting glucose, glucose tolerance test and total cholesterol

Induction of obesity was monitored by monthly measurements of body weight and fasting glucose levels, in addition to a quarterly evaluation of glucose tolerance, with samples collected from tail vein blood. The individual weight measurements were monitored with the aid of a semi-analytical balance (Tepron-Equipment). The fasting glucose test was performed $7 \mathrm{~h}$ following the last food intake, whereas the glucose tolerance test was performed after a 4-h fast. Tests were performed using an AccuChek Active glucometer system (Roche Diagnostics). For assessment of total cholesterol, plasma samples were collected at 0,36 and 51 weeks in the experimental model. Blood samples were collected and placed in microtubes and centrifuged at $1000 \mathrm{rpm}$ at $4^{\circ} \mathrm{C}$ for $10 \mathrm{~min}$ to obtain the plasma, which was stored at $-80^{\circ} \mathrm{C}$ for further analysis in automated equipment, LabMax 560 (LAbtest Diagnostic SA), through the enzymatic colorimetric method.

\section{Cardiac functional analysis}

The cardiac function evaluation included the following: echography, electrocardiography (EKG) and treadmill test performed every quarter. For echography and EKG recordings, mice were anesthetized with inhaled isoflurane $(0.5 \%)$. Transthoracic echocardiography was performed using the Vevo 770 Echosystem (Visual Sonics) equipped with a $30 \mathrm{MHz}$ transducer (Model 707B RMV; Visual Sonics) to acquire images in different acoustic windows, on supine-positioned mice maintained on a thermoregulated plate $\left(37^{\circ} \mathrm{C}\right)$. EKG acquisition was performed using a bipolar I lead, obtained from the Bio Amp PowerLab System (PowerLab 2/20; ADInstruments), allowing for the recording of biological signals in animals with complete electrical isolation. All acquired data was analyzed on Windows Chart 5 (PowerLab). Recordings were bandpass-filtered (1$100 \mathrm{~Hz}$ ) to minimize environmental signal disturbances at a sampling rate of $1 \mathrm{kHz}$. A single-animal motordriven treadmill chamber (LE 8700; Panlab), in which the speed and shock intensity $(\mathrm{mA})$ were controlled by a potentiometer (LE 8700-treadmill control; Panlab), was used to evaluate the animal physical capacity to exercise. Mean room temperature was maintained at $21 \pm 1^{\circ} \mathrm{C}$. After an adaptation period of $30 \mathrm{~min}$ in the treadmill chamber, mice were exercised at five different velocities $(7.2,14.4,28.8,43.2$ and $57.6 \mathrm{~m} / \mathrm{min}$ ), with initial speed increases of $5 \mathrm{~min}$ and from the third speed $10 \mathrm{~min}$ of exercise at each speed. Velocity was increased until the animal could no longer sustain a given speed and remained more than $10 \mathrm{~s}$ on an electrified stainless-steel grid, which provided an electrical stimulus to maintain the mice in motion.

\section{Histopathologic analysis}

Hearts from 38 animals (eight from DMEM-treated mice and 10 from each remaining group) were divided equally such that half of the atria and ventricles was used for histology whereas the other half was used for RNA extraction. Hearts were removed and fixed in buffered $10 \%$ formalin. Heart sections were analyzed using optical microscopy after paraffin embedding, followed by Sirius red staining to evaluate the fibrosis. Images were digitized using a color digital video camera (CoolSnap) adapted to a BX41 microscope (Olympus). The images were analyzed using Image Pro 7.0 (Media Cybernetics).

Blinded analysis was performed on 10 fields captured per heart, identifying areas of fibrosis and avoiding blood vessels (200× magnification). The percentage of fibrosis was estimated in each field using Image-Pro Plus software, where the percentage of the red area was compared with the remaining areas of the field.

\section{Quantitative reverse transcription polymerase chain reaction $(R T-P C R)$ analysis}

Hearts were removed and used for RNA extraction, as described in the previous section. RNA was extracted from heart tissue with TRIzol reagent (Invitrogen) and the concentration was determined using photometric measurement. A High Capacity cDNA Reverse Transcription Kit (Applied Biosystems) was used to synthesize complementary DNA (cDNA) from $1 \mu \mathrm{g}$ of RNA, according to the manufacturer's recommendations. Synthesis of cDNA and RNA expression analysis was performed by Real-Time polymerase chain reaction (PCR) using TaqMan Gene Expression Assay for Adipoq (Mm00456425_m1), Tnf (Mm00443258_m1), Gata4 (Mm00484689_m1), Tgfb1 (Mm00441724_m1), Pparg (Mm01184322_m1), Mmp9 (Mm00442991m1), Timp1 (Mm00441818m1), Cx43 (Mm00439105_m1), Tnni (Mm00437164m1), 
Hgf (Mm01135193m1), Socs3 (Mm 00545913_s1), Col1a1 (Mm 00801666_g1), Igf1 (Mm004395 60_m1) and Vegf (Mm 00437304_m1). All reactions were run in duplicate on an ABI 7500 Real Time PCR System (Applied Biosystems) under standard thermal cycling conditions. A non-template control (NTC) and nonreverse transcription controls (No-RT) were also included. The samples were normalized with Hprt (endogenous control). The threshold cycle (2- $\Delta \Delta \mathrm{Ct})$ method of comparative PCR was used to analyze the results [21]. Data was analyzed using GraphPad software version 6 .

\section{Statistical analysis}

Data were expressed as mean \pm standard error of mean (SEM) for the number of animals in each group. Student $t$ test was used to compare quantitative variables from the two groups at one point. When two or more groups were compared, analysis of variance (ANOVA) was applied, followed by Bonferroni post-test. Significant difference was considered when
$P<0.05$. Statistical analysis was performed with Graph Pad Prism 5.0 software.

\section{Results}

\section{Characterization of MSCs and CM}

Bone marrow-derived MSCs successfully underwent adipogenic, osteogenic and chondrogenic differentiations (Figure 2A-2C) and were characterized using flow cytometry, which showed the expression of MSC cell markers CD29, CD44, CD105 and Sca-1 in the majority of the cells, and low frequency of cells expressing hematopoietic cell markers CD11b and CD45 (Figure 2D). The CM of MSCs was prepared and characterized using a protein array kit for analysis of 111 different cytokines (Supplementary Tables S1-S3). The protein array analysis was able to detect the presence of 19 cytokines, including chemokines, growth factors, adhesion molecules and others proteins involved in apoptosis, inflammation and angiogenesis (Figure 3).
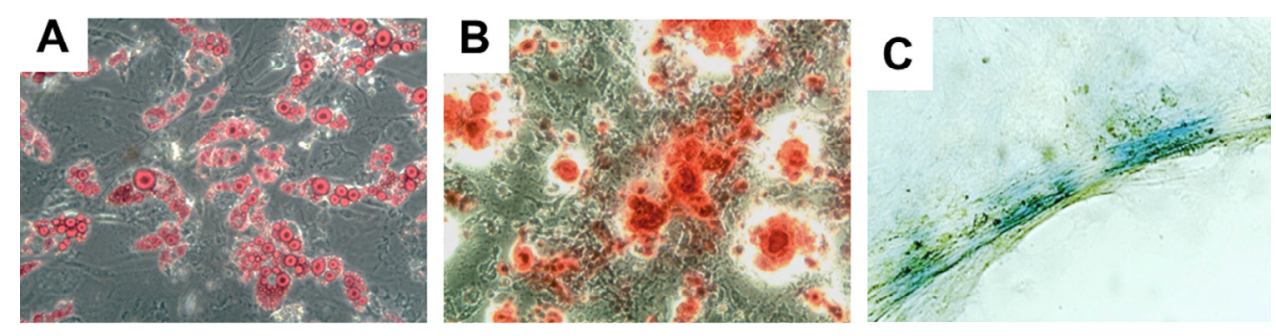

D
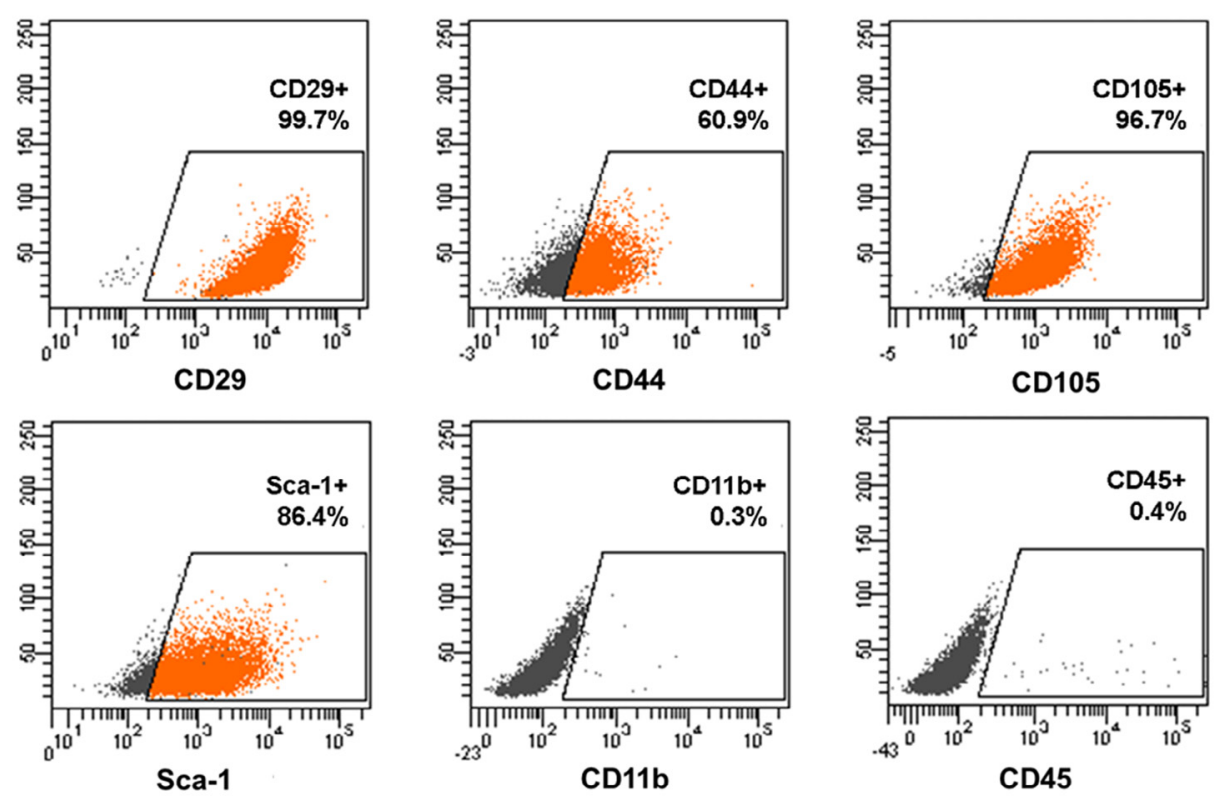

Figure 2. Characterization of bone marrow MSCs from C57B1/6 mice. MSCs were differentiated into oil red O-positive adipocytes (a), alizarin red S-positive osteocytes (b) and alcian blue-positive chondrocytes (c). (d) Flow cytometric analyses showed that MSCs (passage 8) were positive for CD105, Sca-1, CD29 and CD44 and negative for CD11b and CD45. 

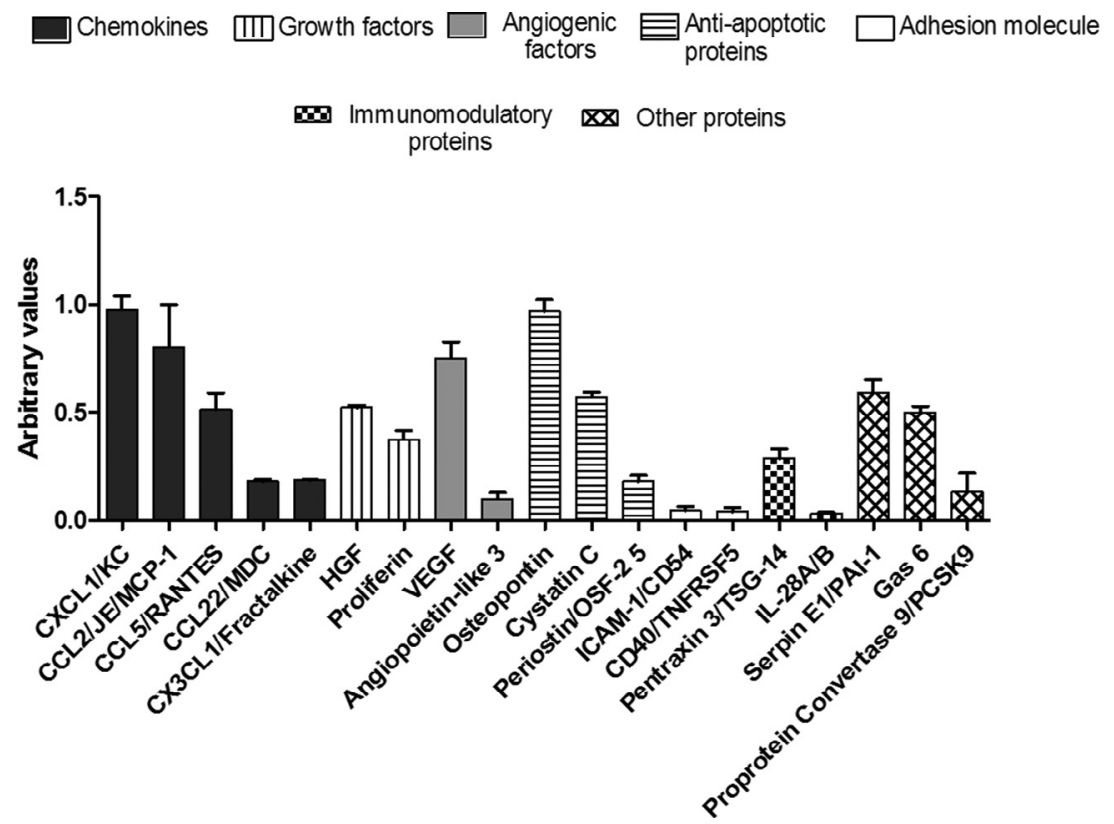

Figure 3. Characterization of CM by protein array. Analysis of protein contents in CM was done using an antibody-based protein detection array to detect 111 proteins, including cytokines, adhesion molecule and trophic factors. Chemiluminescent cytokine array data were semi-quantified by evaluating the intensity of each spot in a gray-scale level. The density for each protein is shown as mean \pm standard deviation (SD) of duplicate spots.

HFD removal in obese mice reduces body weight, fasting glucose, glucose tolerance test and total cholesterol

The introduction of HFD for 36 weeks caused a significant increase in body weight, fasting glucose, glucose tolerance test (GTT) and total cholesterol, as compared with standard diet-fed mice. Statistically significant differences in body weight and fasting glucose were found after 28 weeks of induction (Figure 4A and 4B). After 36 weeks, HFD was withdrawn and all animals were fed with a standard diet, while receiving MSCs, CM or DMEM administrations. Eight weeks after the end of the treatment (51 weeks) all mice improved their blood levels of glucose and cholesterol, while decreasing body weight, with no significant differences between the different treatment groups (Figure 4).

HFD induced glucose intolerance, when compared with mice fed with standard diet, as shown by an impairment in reducing plasma glucose levels to the initial glucose concentration values after $120 \mathrm{~min}$ of intraperitoneal injection of glucose (Figure 5A and $5 B)$. Glucose intolerance was also normalized at the 51 st week, independently of treatment (Figure 5C).

\section{Administration of MSCs and CM reverses cardiac function alterations in obese mice}

Thirty-six weeks after HFD induction, obese mice developed different cardiac arrhythmias, such as first degree atrioventricular (AV) block, atrial conduction disturbance, junctional rhythm, ventricular conduction disturbance, ventricular bigeminism and polymorphic ventricular tachycardia, whereas no disturbances were recorded in mice fed with standard diet. Treatment with MSCs or CM reversed cardiac arrhythmias. In contrast, obese HFD mice treated with DMEM maintained or worsened cardiac rhythm disturbances (Table II; Figure 6).

A significant reduction of running distance was observed in obese mice when compared with controls at the 36-week time point (Table III). Importantly, the physical exercise capacity was partially recovered in MSC- and CM-treated obese mice, as shown by the run distance, when compared with the HFD group at 36 weeks (Table III). Compared with HFD mice at 36 weeks, the DMEM-treated group had no recovery in physical capacity. The cardiac structural and hemodynamic evaluations performed by echocardiogram during systole and diastole did not detect any cardiac alterations (data not shown).

\section{MSCs regulate the expression levels of inflammatory cytokines and transcription factors in hearts of obese mice}

Next, we performed an analysis by quantitative reverse transcription PCR (RT-qPCR) of cardiac tissues at 51 weeks. Adiponectin gene expression was reduced inDMEM-treated HFD mice compared with standard diet controls (Figure 7A). Treatment with MSCs or CM restored the levels of adiponectin gene expression to levels similar to nonobese controls 

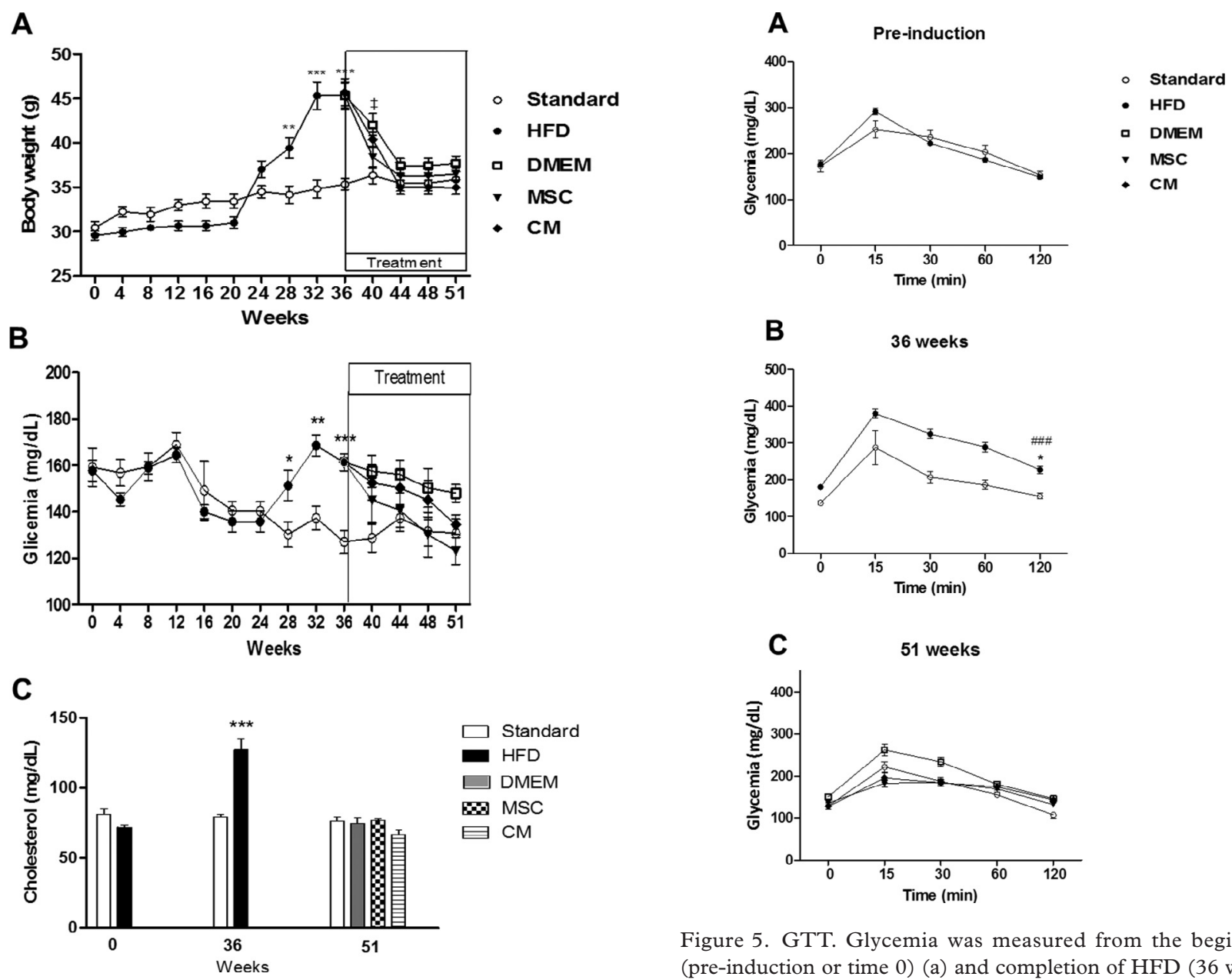

Figure 4. Analysis of body weight, fasting glucose and total cholesterol. Body weight (a) and fasting glucose (b) were measured monthly until the completion of the experiment (51 weeks). (c) Total cholesterol at basal line, 36 weeks of induction and 8 weeks after treatment. Following the completion of the HFD-induced obesity (36 weeks), mice returned to standard diet and received MSCs or CM or DMEM treatments until 51 weeks. Values are expressed as mean \pm SEM of 8 to 10 mice per group. HFD mice versus standard diet mice; ${ }^{\star \star \star} P \leq 0.001 ;{ }^{\star \star} P \leq 0.01 ;{ }^{\star} P \leq 0.05$. Standard diet mice versus DMEM-treated; ${ }^{\ddagger} P \leq 0.05$.

(Figure 7A). The gene expression of tumor necrosis factor (TNF) $\alpha$, vascular endothelial growth factor (VEGF $\alpha$ ), transforming growth factor (TGF) $\beta 1$ and insulin growth factor 1 (IGF-1) was increased in the hearts of obese mice treated with DMEM, compared with nonobese controls (Figure 7B-7E). Treatment with MSCs, but not with CM, significantly reduced the gene expression levels of TGF $\beta 1$ and IGF-1 (Figures 7D and E). Additionally, the transcriptional factors suppressor of cytokine signaling 3 (SOCS3) and peroxisome proliferator activated receptor gamma (PPAR $\gamma$ ) were significantly increased in DMEM and CM, but not in MSCs, when compared with the nonobese control group (Figures 7F and G). GATA-4 and connexin-43 transcriptional levels

Figure 5. GTT. Glycemia was measured from the beginning (pre-induction or time 0) (a) and completion of HFD (36 weeks) (b), every 3 months, until the end of the trial period (51 weeks) (c). Following the completion of the HFD-induced DM2 and obesity, mice returned to standard diet and received MSCs, CM or DMEM with treatment. Values are expressed as mean \pm SEM of 8 to 10 mice/group. HFD mice versus standard diet mice; ${ }^{\star} P \leq 0.05$. HFD mice in time $120 \mathrm{~m}$ versus HFD mice in basal time or versus HFD mice in time $120 \mathrm{~m}$; \#\#\# $\leq 0.001$.

were significantly reduced by treatments with MSCs and CM when compared with DMEM-treated controls (Figures $7 \mathrm{H}$ and $7 \mathrm{I}$ ), whereas troponin I was only modulated by MSC therapy (Figure 7J).

\section{Reversion of HFD-induced heart fibrosis in the heart after MSC and CM administration}

The presence and degree of fibrosis were evaluated in the heart sections of obese mice and nonobese controls (Figure 8A-8D). DMEM-treated obese mice had a significantly higher percentage of cardiac fibrosis at week 51 when compared with mice fed with standard diet (Figure 8E). Both MSC and CM administrations promoted a significant reduction in fibrosis in the hearts of obese mice when compared with DMEM-treated obese mice (Figure 8E). Analysis of gene expression in the heart tissue showed 


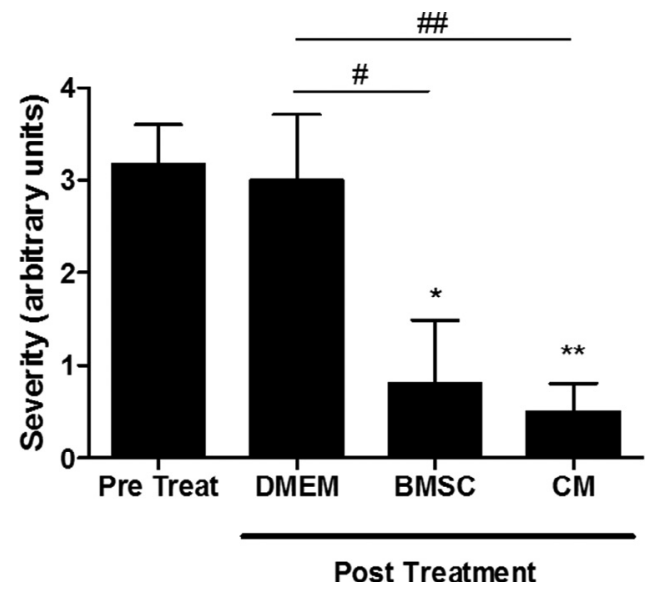

Figure 6. Cardiac conduction disturbances in arbitrary units in C57Bl/6 mice before (pre-treatment) and 2 months after treatment (post-treatment). Degree of severity: 0, no cardiac conduction disturbances; 1, first-degree atrium-ventricular block; 2, intraatrium conduction disturbance; 3, junctional rhythm; 4, intraventricular conduction disturbance; 5 , ventricular bigeminism; 6 , polymorphic ventricular tachycardia; and $7, \mathrm{AV}$ dissociation. ${ }^{\star} P \leq 0.05$. Pretreatment versus bone marrow stromal cell (BMSC)treated group vs $C M$-treated group. $\# P \leq 0.05$; \#\#P $\leq 0.01$ DMEMtreated versus BMSCs-treated mice versus CM-treated mice.

reduction of type I collagen by MSC and CM administration, reaching levels similar to those of mice fed with standard diet (Figure 8F). Finally, the gene expression of MMP9 and TIMP1, two genes associated with extracellular matrix remodeling, was normalized by treatment with MSCs, but not with CM (Figure 8G and $8 \mathrm{H})$.

Table III. Exercise capacity (run distance in $\mathrm{m}$ ) of mice submitted to standard diet or HFD.

\begin{tabular}{lccc}
\hline & Preinduction & $36 \mathrm{wk}$ & $51 \mathrm{wk}$ \\
\hline Standard (n=10) & $615 \pm 29.3$ & $648 \pm 25.6$ & $627 \pm 37.3$ \\
HFD ( $=28)$ & $668 \pm 20.0$ & $317 \pm 15.8^{\mathrm{c}, \mathrm{d}}$ & - \\
HFD + DMEM & - & - & $426 \pm 21.3^{\mathrm{c}, \mathrm{h}}$ \\
$(\mathrm{n}=08)$ & - & - & $524 \pm 30.8^{\mathrm{a}, \mathrm{f}}$ \\
$\begin{array}{c}\text { HFD + MSC } \\
(\mathrm{n}=10)\end{array}$ & - & - & $471 \pm 12.2^{\mathrm{b}, \mathrm{e}, \mathrm{g}}$ \\
$\begin{array}{c}\text { HFD }+ \text { CM } \\
(\mathrm{n}=10)\end{array}$ & - & - & \\
\hline
\end{tabular}

Values are expressed as mean \pm SEM.

${ }^{\mathrm{a}} P \leq 0.05$.

${ }^{\mathrm{b}} P \leq 0.01$.

${ }^{\mathrm{c}} P \leq 0.001$; HFD mice versus standard diet-fed mice.

${ }^{\mathrm{d}} P \leq 0.001$; HFD mice in 36 weeks versus HFD mice in pre induction period.

${ }^{\mathrm{e}} P \leq 0.05$.

${ }^{\mathrm{f}} P \leq 0.01$; HFD mice in 36 weeks versus MSCs-treated mice and CM-treated mice.

${ }^{\mathrm{g}} P \leq 0.05$.

${ }^{\mathrm{h}} P \leq 0.001$; HFD mice in preinduction period versus DMEMtreated mice and CM-treated mice. 

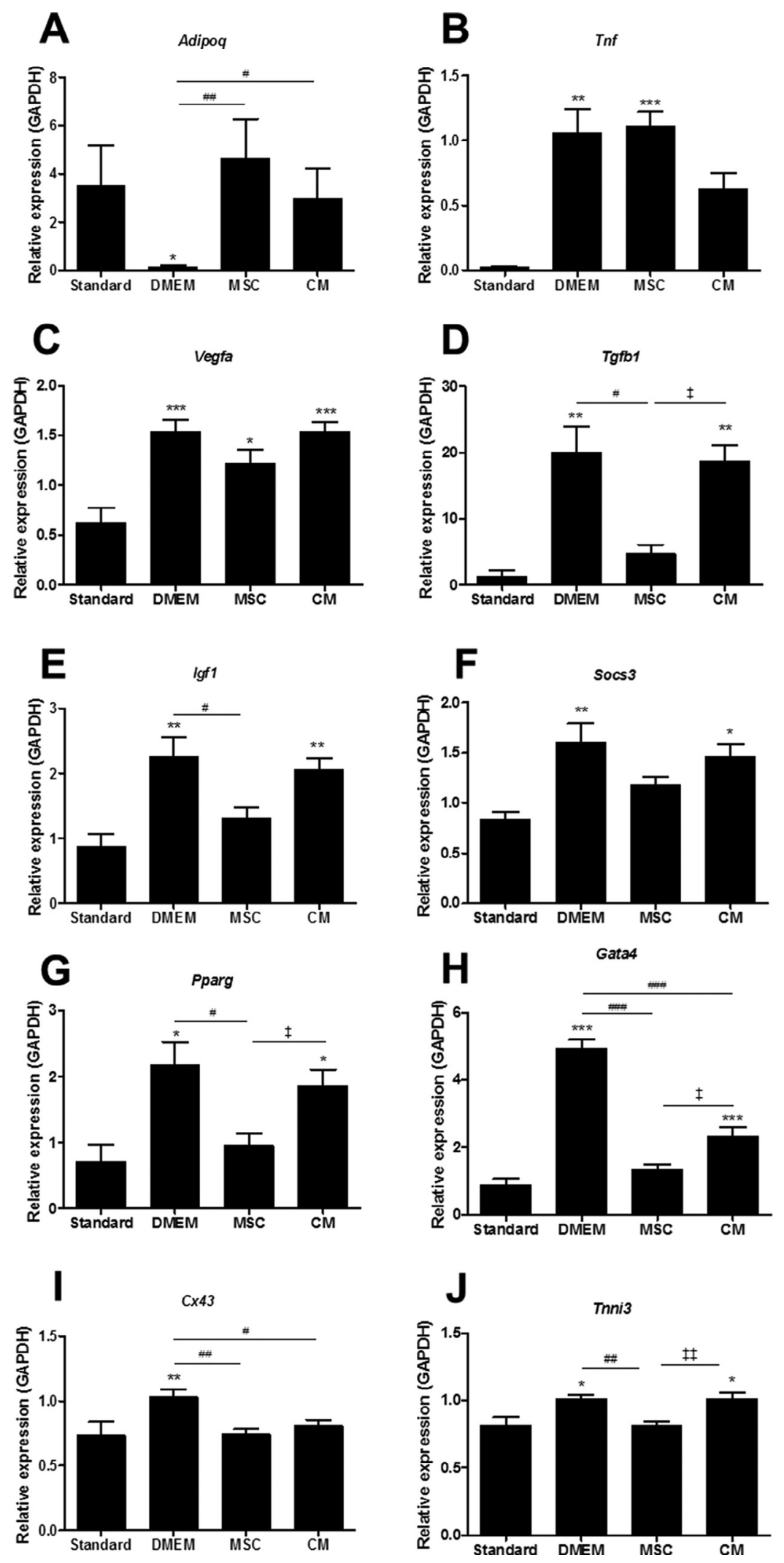

Figure 7. RT-qPCR in heart tissue cytokines and transcription factors. Representative values of $\operatorname{Adipoq}$ (a), Tnf (b), Vegfa (c), Tgf- $\beta 1$ (d), Socs3 (e), Gata4 (f), Pparg (g), Igf1 (h), Tnni3 (i) and Cx43 (j). Expression obtained 8 weeks after the end of treatments, which corresponded to 51 weeks of study. (Values are expressed as mean \pm SEM of 7 to 9 mice/group.) Standard diet-fed mice versus treated mice group; ${ }^{\star} P \leq 0.05 ;{ }^{\star \star} P \leq 0.01 ;{ }^{\star \star \star} P \leq 0.001$. DMEM-treated mice versus MSC-treated or CM-treated mice; $\# P \leq 0.05 ; \# \# P \leq 0.01$; $\# \# \# P \leq 0.001$. MSC-treated mice versus CM-treated mice; $\ddagger P \leq 0.05 ; \ddagger \ddagger P \leq 0.01$. 

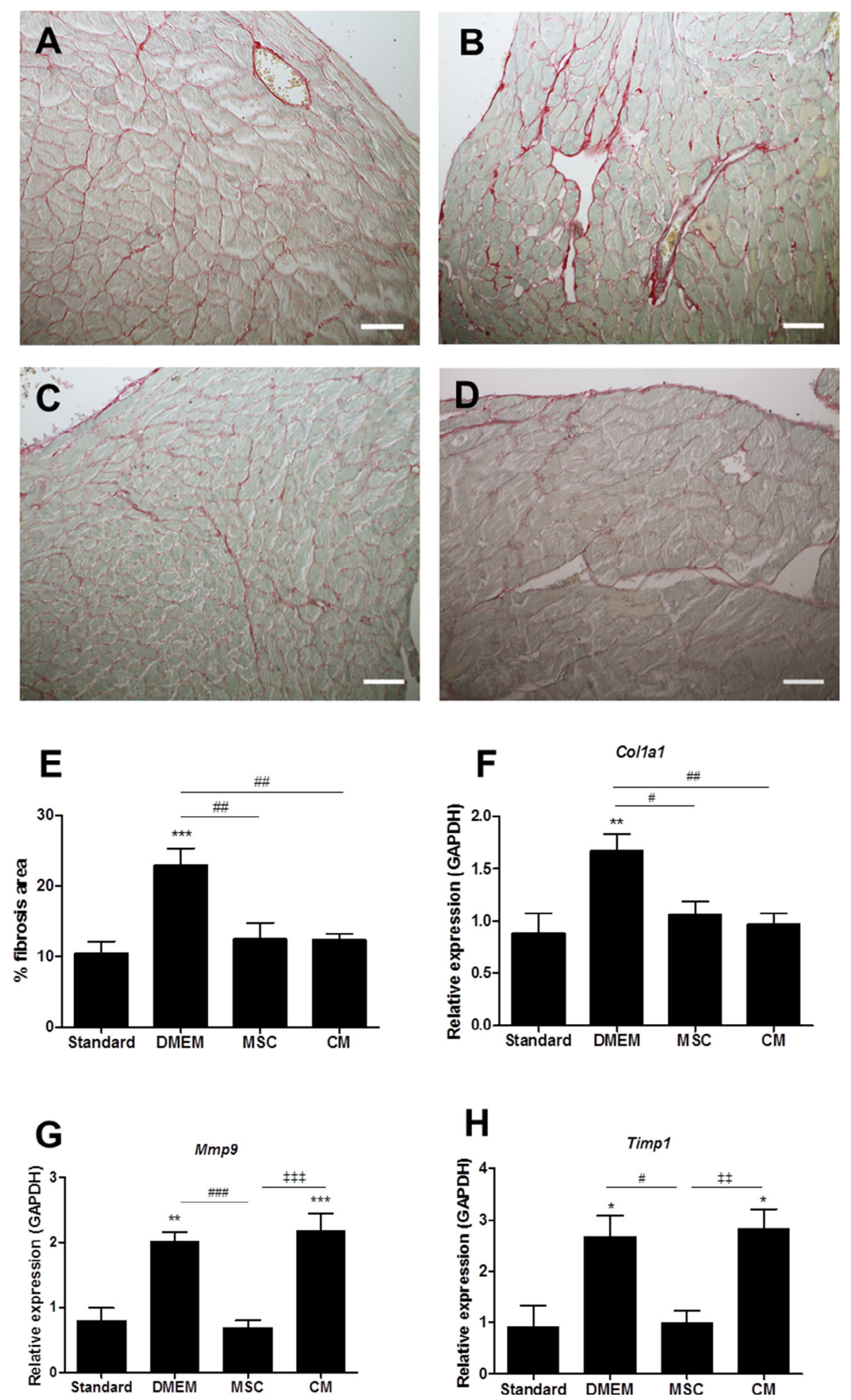

Figure 8. MSC and CM administration reduces HFD-induced heart fibrosis. Heart sections of mice fed with standard diet (a), or with HFD treated with DMEM $(n=8)(b)$, MSCs $(n=10)(c)$ and CM $(n=10)(d)$ were stained with sirius red and used for morphometric analysis of the percentage of fibrosis area (e). Relative gene expression of Col1a1 (f), Mmp9 (g) and Timp1 (h) in the heart. Values are expressed as mean \pm SEM. Standard diet mice versus DMEM-treated mice; ${ }^{\star} P \leq 0.05 ;{ }^{\star \star} P \leq 0.01,{ }^{\star \star \star} P \leq 0.001$. DMEM-treated mice versus MSC-treated mice or versus CM-treated mice; $\# P \leq 0.05, \# \# P \leq 0.01$. MSC-treated mice versus $C M$-treated mice; $\ddagger \ddagger P \leq 0.01$; $\ddagger \ddagger \ddagger P \leq 0.001$.

\section{Discussion}

Due to the growing prevalence of obesity, it is crucial to develop new treatments to control cardiac repercussions and comorbidities. Here we show that treatment with MSCs efficiently reverses cardiac abnormalities induced by obesity in mice fed with a HFD. This was shown by recovery of physical exercise capacity, arrhythmias reversal, regulation of gene expression and reduction of fibrosis in the heart tissue. 
Importantly, most of the therapeutic effects found in MSC-treated mice were also observed in mice treated with MSC CM.

In the present study, $\mathrm{C} 57 \mathrm{Bl} / 6$ male mice fed with a diet enriched with lard saturated fat developed obesity and myocardial disturbances, which mimics the physiological effects associated with human adiposity through nutritional behavior [22-24]. Previous studies have shown that lifestyle changes, such as exercise and balanced diet with low levels of saturated fatty acids, trans fatty acid and cholesterol, are essential to control blood glucose and reduce cardiovascular risk $[25,26]$. Here we show that obese mice in which HFD was replaced by the standard diet had a reduction in body weight, glucose levels and total cholesterol levels, regardless of the treatment, in accordance with our previous study [19]. In spite of that, diet change did not improve the established cardiac alterations, such as conduction disturbances, decreased exercise capacity, cardiac fibrosis and transcriptional profile. In contrast, administration of MSCs was able to induce significant morphological and functional improvements in the hearts of HFD-fed mice.

After administration of MSCs or CM, we observed reduced collagen levels and decreased fibrosis. These effects probably are associated with the decreased severity of arrhythmias observed because increased deposition of ECM among cardiomyocyte layers may interrupt their electrical coupling, resulting in weakened cardiac contraction and increased risk of arrhythmia [27]. We investigated by RT-qPCR analysis the expression of TGF- $\beta$, MMP-9 and TIMP-1 genes, factors that could be associated with fibrosis development. It is known that TGF- $\beta$ is a central mediator involved in the repair process, and its excessive secretion results in altered deposition of extracellular matrix (ECM) proteins and collagen deposition in the heart [28], by stimulation of fibroblasts to myofibroblasts differentiation, while activating Smad3 signaling pathway to promote ECM proteins synthesis and matrix preservation through increased expression of tissue inhibitors of metalloproteinases (TIMPs) [29]. We found that treatment with MSCs was able to restore the expression of TIMP-1 and MMP-9 to levels similar to control mice.

Similarly, PPAR $\gamma$ gene expression levels were also elevated in HFD mice, but were modulated in mice treated with MSCs. PPAR $\gamma$, a nuclear receptor and transcription factor, was previously found to be upregulated in the hearts of patients with metabolic syndrome and cardiac hypertrophy, in response to injury $[30,31]$.

In the present study, we analyzed the cardiac expression of genes involved in the process of cardiac hypertrophy and remodeling, including adiponectin, IGF-1 and GATA-4. Adiponectin has been previously demonstrated to be cardioprotective and to inhibit cardiac remodeling through anti-inflammatory and prosurvival mechanisms $[32,33]$. We found that adiponectin expression in the hearts of mice treated with MSCs or CM was similar to control mice, but was reduced in DMEM-treated HFD mice. In contrast, GATA4, a transcription factor that regulates the expression of cardiac-specific genes, was found to be increased by HFD in our study and by others, being associated with cardiac hypertrophy [6]. Importantly, treatments with MSCs or CM were able to restore GATA-4 messenger RNA (mRNA) levels to a pattern similar to control mice. Futhermore, GATA- 4 is involved in the regulation of troponin I [34], which, when highly expressed, has stronger correlation with increased risk and severity of cardiac arrhythmias [35-37]. In the present study, only MSC-treated mice had the same troponin I expression levels as control mice after the treatment, suggesting its participation in cardiac recovery. IGF-1 has also been associated with cardiac repair during remodeling [38] by inducing expression of TGF$\beta$, which directly stimulates collagen expression [39]. Thus, the reduction of IGF1 expression in bone marrow stromal cell (BMSC)-treated mice described in the present study could be one of the mechanisms involved in the improvement of cardiac function.

The role of suppressor of cytokine signaling (SOCS) proteins in the pathogenic mechanisms of diabetes are one of the most investigated factors of the last few years [40]. Although the correlation between SOCS3 expression and insulin resistance has been demonstrated before by detection of high levels of SOCS3 in insulin-sensitive tissues from diabetic patients $[41,42]$ and animals that developed insulin resistance $[43,44]$, in the present study, cardiac expression level of SOCS3 was similar in control mice and HFD MSC-treated mice, suggesting an improvement in cardiac intracellular signaling to insulin.

Alterations in connexin 43 expression and function have been described in experimental models of diabetes [45], hypercholesterolemia [46] and HFD [47]. These include altered pattern of phosphorylation, leading to increased propensity to proteolytic degradation [45]. It has been demonstrated that altered connexin 43 expression favors arrhythmia [48]. The increased connexin $43 \mathrm{mRNA}$ levels induced by HFD in our study may reflect a compensatory response to decreased levels of functional protein, as previously described [46]. Interestingly, connexin- 43 mRNA levels were found to be decreased to levels similar to control mice, in the groups treated with MSCs or CM, which correlated with improvements in arrhythmias. Another compensatory mechanisms could be the elevated expression of VEGF detected in HFD mice because it is known that cardiac insult, fibrosis and arrhythmias 
lead to VEGF production increase, which in turn regulate the connexin 43 expression [49,50].

The CM from MSCs contains several secreted factors and this suggests a probable mechanism of paracrine action. MSC CM was previously shown to promote cardiac repair in different experimental models $[17,51]$. The characterization of CM by protein array revealed the presence of cytokines, growth factors, chemokines, angiogenic factors, anti-apoptotic proteins and adhesion molecules, as described previously [52]. It has been shown that MSCs secrete a wide range of cytokines and growth factors with anti-inflammatory, anti-apoptotic, angiogenic and anti-fibrotic effects, which may contribute to the observed therapeutic effects of cell therapy in the heart $[53,54]$. Besides soluble mediators, MSCs also release extracellular vesicles (EVs) that contribute to tissue repair and regeneration through the transfer of a repertoire of mRNAs, micro RNAs, DNA, proteins and lipids [55-57]. This process may be also involved in the mechanisms of action of MSCs and CM in our model, which will require further studies for proper investigation.

In conclusion, our results suggest that MSCs and $\mathrm{CM}$ exert a therapeutic effect on cardiac alterations associated with obesity. The alterations found in our experimental mode, include cardiac arrhythmias, conduction disturbances and fibrosis, which were sustained even after diet change and weight loss, but reversed after cell therapy. The effects of MSC CM support the relevance of MSC's secreted factors in the mechanisms of action involved.

\section{Acknowledgments}

We thank Dr. Carine Azevedo (FIOCRUZ) for technical assistance in morphometrical analysis. This work was supported by grant 465656/2014-5 from Conselho Nacional de Desenvolvimento Científico e Tecnológico $(\mathrm{CNPq})$, by Fundação de Amparo à Pesquisa do Estado da Bahia (FAPESB) and Financiadora de Estudos e Projetos (FINEP).

Disclosure of interests: The authors indicate no potential conflicts of interest.

\section{References}

[1] Szendroedi J, Roden M. Ectopic lipids and organ function. Curr Opin Lipidol 2009;20:50-6.

[2] van Herpen NA, Schrauwen-Hinderling VB. Lipid accumulation in non-adipose tissue and lipotoxicity. Physiol Behav 2008;94:231-41.

[3] Abel ED, Litwin SE, Sweeney G. Cardiac remodeling in obesity. Physiol Rev 2008;88:389-419.

[4] Messerli FH. Cardiovascular effects of obesity and hypertension. Lancet 1982;1:1165-8.

[5] Avelar E, Cloward TV, Walker JM, Farney RJ, Strong M, Pendleton RC, et al. Left ventricular hypertrophy in severe obesity: interactions among blood pressure, nocturnal hypoxemia, and body mass. Hypertension 2007;49:34-9.

[6] Wang Z, Li L, Zhao H, Peng S, Zuo Z. Chronic high fat diet induces cardiac hypertrophy and fibrosis in mice. Metabolism 2015;64:917-25.

[7] Casis O, Echevarria E. Diabetic cardiomyopathy: electromechanical cellular alterations. Curr Vasc Pharmacol 2004;2:237-48.

[8] Abdi R, Fiorina P, Adra CN, Atkinson M, Sayegh MH. Immunomodulation by mesenchymal stem cells: a potential therapeutic strategy for type 1 diabetes. Diabetes 2008;57: 1759-67.

[9] Nauta AJ, Westerhuis G, Kruisselbrink AB, Lurvink EG, Willemze R, Fibbe WE. Donor-derived mesenchymal stem cells are immunogenic in an allogeneic host and stimulate donor graft rejection in a nonmyeloablative setting. Blood 2006;108:2114-20.

[10] Molina EJ, Palma J, Gupta D, Torres D, Gaughan JP, Houser $\mathrm{S}$, et al. Reverse remodeling is associated with changes in extracellular matrix proteases and tissue inhibitors after mesenchymal stem cell (MSC) treatment of pressure overload hypertrophy. J Tissue Eng Regen Med 2009;3:8591.

[11] Psaltis PJ, Zannettino AC, Worthley SG, Gronthos S. Concise review: mesenchymal stromal cells: potential for cardiovascular repair. Stem Cells 2008;26:2201-10.

[12] Heldman AW, DiFede DL, Fishman JE, Zambrano JP, Trachtenberg BH, Karantalis V, et al. Hare, Transendocardial mesenchymal stem cells and mononuclear bone marrow cells for ischemic cardiomyopathy: the TAC-HFT randomized trial. JAMA 2014;311:62-73.

[13] Karantalis V, Suncion-Loescher VY, Bagno L, Golpanian S, Wolf A, Sanina C, et al. Synergistic effects of combined cell therapy for chronic ischemic cardiomyopathy. J Am Coll Cardiol 2015;66:1990-9.

[14] van Velthoven CT, Kavelaars A, van Bel F, Heijnen CJ. Regeneration of the ischemic brain by engineered stem cells: fuelling endogenous repair processes. Brain Res Rev 2009;61:1-13.

[15] Gnecchi M, Zhang Z, Ni A, Dzau VJ. Paracrine mechanisms in adult stem cell signaling and therapy. Circ Res 2008;103: 1204-19.

[16] Nakanishi C, Yamagishi M, Yamahara K, Hagino I, Mori H, Sawa Y, et al. Activation of cardiac progenitor cells through paracrine effects of mesenchymal stem cells. Biochem Biophys Res Commun 2008;374:11-16.

[17] Timmers L, Lim SK, Hoefer IE, Arslan F, Lai RC, van Oorschot AA, et al. Human mesenchymal stem cellconditioned medium improves cardiac function following myocardial infarction. Stem Cell Res 2011;6:206-14.

[18] Cai M, Shen R, Song L, Lu M, Wang J, Zhao S, et al. Bone Marrow Mesenchymal Stem Cells (BM-MSCs) improve heart function in swine myocardial infarction model through paracrine effects. Sci Rep 2016;6:28250.

[19] Daltro PS, Alves PS, Castro MF, Azevedo CM, Vasconcelos $\mathrm{JF}$, Allahdadi KJ, et al. Administration of granulocyte-colony stimulating factor accompanied with a balanced diet improves cardiac function alterations induced by high fat diet in mice. BMC Cardiovasc Disord 2015;15:162.

[20] Carpentier G. Contribution: Protein Array Analyzer for ImageJ. Image J News, 2010.

[21] Schmittgen TD, Livak KJ. Analyzing real-time PCR data by the comparative CT method. Nat Protoc 2008;3:1101-8.

[22] Jang I, Hwang D, Lee J, Chae K, Kim Y, Kang T, et al. Physiological difference between dietary obesity-susceptible and obesity-resistant Sprague Dawley rats in response to moderate high fat diet. Exp Anim 2003;52:99-107. 
[23] Carroll JF, Zenebe WJ, Strange TB. Cardiovascular function in a rat model of diet-induced obesity. Hypertension 2006; 48:65-72.

[24] Okere IC, Young ME, McElfresh TA, Chess DJ, Sharov VG, Sabbah HN, et al. Low carbohydrate/high-fat diet attenuates cardiac hypertrophy, remodeling, and altered gene expression in hypertension. Hypertension 2006;48:1116-23.

[25] de Simone G, Devereux RB, Chinali M, Lee ET, Galloway JM, Barac A, et al. Diabetes and incident heart failure in hypertensive and normotensive participants of the Strong Heart Study. J Hypertens 2010;28:353-60.

[26] Cheng D. Prevalence, predisposition and prevention of type II diabetes. Nutr Metab (Lond) 2005;2:29.

[27] Spach MS, Boineau JP. Microfibrosis produces electrical load variations due to loss of side-to-side cell connections: a major mechanism of structural heart disease arrhythmias. Pacing Clin Electrophysiol 1997;20:397-413.

[28] MacKenna D, Summerour SR, Villarreal FJ. Role of mechanical factors in modulating cardiac fibroblast function and extracellular matrix synthesis. Cardiovasc Res 2000; $46: 257-63$.

[29] Verrecchia F, Chu ML, Mauviel A. Identification of novel TGF-beta /Smad gene targets in dermal fibroblasts using a combined cDNA microarray/promoter transactivation approach. J Biol Chem 2001;276:17058-62.

[30] Krishnan J, Suter M, Windak R, Krebs T, Felley A, Montessuit C, et al. Activation of a HIF1alpha-PPARgamma axis underlies the integration of glycolytic and lipid anabolic pathways in pathologic cardiac hypertrophy. Cell Metab 2009;9:512-24.

[31] Marfella R, Di Filippo C, Portoghese M, Barbieri M, Ferraraccio F, Siniscalchi M, et al. Myocardial lipid accumulation in patients with pressure-overloaded heart and metabolic syndrome. J Lipid Res 2009;50:2314-23.

[32] Ouchi N, Shibata R, Walsh K. Targeting adiponectin for cardioprotection. Expert Opin Ther Targets 2006;10:573-81.

[33] Smith CC, Yellon DM. Adipocytokines, cardiovascular pathophysiology and myocardial protection. Pharmacol Ther 2011;129:206-19.

[34] Ku PM, Chen LJ, Liang JR, Cheng KC, Li YX, Cheng JT. Molecular role of GATA binding protein 4 (GATA-4) in hyperglycemia-induced reduction of cardiac contractility. Cardiovasc Diabetol 2011;10:57.

[35] Missov E, Calzolari C, Pau B. Circulating cardiac troponin I in severe congestive heart failure. Circulation 1997;96:29538.

[36] Antman EM, Tanasijevic MJ, Thompson B, Schactman M, McCabe $\mathrm{CH}$, Cannon $\mathrm{CP}$, et al. Cardiac-specific troponin I levels to predict the risk of mortality in patients with acute coronary syndromes. N Engl J Med 1996;335:1342-9.

[37] Apple FS. Increased concentrations of cardiac troponin I are equivalent to increased cardiac troponin $\mathrm{T}$ in identifying chest pain patients at short-term risk of myocardial infarction. Clin Chem 1998;44:1786-9.

[38] Czubryt MP. Common threads in cardiac fibrosis, infarct scar formation, and wound healing. Fibrogenesis Tissue Repair 2012;5:19-29.

[39] Pugliese G, Pricci F, Romeo G, Pugliese F, Mené P, Giannini $S$, et al. Upregulation of mesangial growth factor and extracellular matrix synthesis by advanced glycation end products via a receptor-mediated mechanism. Diabetes 1997;46:1881-7.

[40] Suchy D, Łabuzek K, Machnik G, Kozłowski M, Okopień B. SOCS and diabetes-ups and downs of a turbulent relationship. Cell Biochem Funct 2013;31:181-95.

[41] Rieusset J, Bouzakri K, Chevillotte E, Ricard N, Jacquet D, Bastard JP, et al. Suppressor of cytokine signaling 3 expression and insulin resistance in skeletal muscle of obese and type 2 diabetic patients. Diabetes 2004;53:2232-41.

[42] Feng X, Tang H, Leng J, Jiang Q. Suppressors of cytokine signaling (SOCS) and type 2 diabetes. Mol Biol Rep 2014;41: 2265-74.

[43] Ueki K, Kondo T, Kahn CR. Suppressor of cytokine signaling 1 (SOCS-1) and SOCS-3 cause insulin resistance through inhibition of tyrosine phosphorylation of insulin receptor substrate proteins by discrete mechanisms. Mol Cell Biol 2004; 24:5434-46.

[44] Spangenburg EE, Brown DA, Johnson MS, Moore RL. Exercise increases SOCS-3 expression in rat skeletal muscle: potential relationship to IL-6 expression. J Physiol 2006; 572:839-48

[45] Lin H, Ogawa K, Imanaga I, Tribulova N. Remodeling of connexin 43 in the diabetic rat heart. Mol Cell Biochem 2006;290:69-78.

[46] Lin LC, Wu CC, Yeh HI, Lu LS, Liu YB, Lin SF, et al. Downregulated myocardial connexin 43 and suppressed contractility in rabbits subjected to a cholesterol-enriched diet. Lab Invest 2005;85:1224-37.

[47] Görbe A, Varga ZV, Kupai K, Bencsik P, Kocsis GF, Csont $\mathrm{T}$, et al. Cholesterol diet leads to attenuation of ischemic preconditioning-induced cardiac protection: the role of connexin 43. Am J Physiol Heart Circ Physiol 2011;300: H1907-13.

[48] Poelzing S, Rosenbaum DS. Altered connexin43 expression produces arrhythmia substrate in heart failure. Am J Physiol Heart Circ Physiol 2004;287:H1762-70.

[49] Chintalgattu V, Nair D, Katwa LC. Cardiac myofibroblasts: a novel source of vascular endothelial growth factor (VEGF) and its receptors Flt-1 and KDR. J Mol Cell Cardiol 2003; 3:277-86.

[50] Pimentel RC, Yamada KA, Kleber AG, Saffitz JE. Autocrine regulation of myocyte $\mathrm{Cx} 43$ expression by VEGF. Circ Res 2002;90:671-7.

[51] Pawitan JA. Prospect of stem cell conditioned medium in regenerative medicine. Biomed Res Int 2014;2014:965849.

[52] Parekkadan B, van Poll D, Suganuma K, Carter EA, Berthiaume F, Tilles AW, et al. Mesenchymal stem cell-derived molecules reverse fulminant hepatic failure. PLoS ONE 2007;2:e941.

[53] Alfaro MP, Pagni M, Vincent A, Atkinson J, Hill MF, Cates $\mathrm{J}$, et al. The Wnt modulator sFRP2 enhances mesenchymal stem cell engraftment, granulation tissue formation and myocardial repair. Proc Natl Acad Sci USA 2008;105:1836671.

[54] Korf-Klingebiel M, Kempf T, Sauer T, Brinkmann E, Fischer P, Meyer GP, et al. Bone marrow cells are a rich source of growth factors and cytokines: implications for cell therapy trials after myocardial infarction. Eur Heart J 2008;29:2851-8.

[55] Collino F, Bruno S, Deregibus MC, Tetta C, Camussi G. MicroRNAs and mesenchymal stem cells. Vitam Horm 2011;87:291-320.

[56] Camussi G, Deregibus MC, Bruno S, Grange C, Fonsato V, Tetta C. Exosome/ microvesicle-mediated epigenetic reprogramming of cells. Am J Cancer Res 2011;1:98-110.

[57] Nawaz M, Fatima F, Zanetti BR, Martins IL, Schiavotelo NL, Mendes ND, et al. Microvesicles in gliomas and medulloblastomas: an overview. J Cancer Ther 2014;5:182-91.

\section{Appendix: Supplementary material}

Supplementary data to this article can be found online at doi:10.1016/j.jcyt.2017.07.002. 